\title{
Dilated cardiomyopathy with Graves disease in a young child
}

\author{
Yu Jung Choi, MD, \\ Jun Ho Jang, MD, \\ So Hyun Park, MD, \\ Jin-Hee Oh, MD, \\ Dae Kyun Koh, MD
}

Department of Pediatrics, St. Vincent's Hospital, The Catholic University of Korea, Suwon, Korea
Received: 6 November, 2015

Revised: 2 Dcember, 2015

Accepted: 8 Dcember, 2015

Address for correspondence: So Hyun Park, MD

Department of Pediatrics, St. Vincent Hospital, The Catholic University of Korea, 93 Jungbu-daero, Paldal-gu, Suwon 16247, Korea

Tel: +82-31-249-8220

Fax: +82-31-257-9111

E-mail: nicedoc@catholic.ac.kr
Graves disease (GD) can lead to complications such as cardiac arrhythmia and heart failure. Although dilated cardiomyopathy (DCMP) has been occasionally reported in adults with GD, it is rare in children. We present the case of a 32-month-old boy with DCMP due to GD. He presented with irritability, vomiting, and diarrhea. He also had a history of weight loss over the past few months. On physical examination, he had tachycardia without fever, a mild diffuse goiter, and hepatomegaly. The chest radiograph showed cardiomegaly with pulmonary edema, while the echocardiography revealed a dilated left ventricle with an ejection fraction (EF) of $28 \%$. The thyroid function test (TFT) showed elevated serum T3 and decreased thyroid stimulating hormone (TSH) levels. The TSH receptor autoantibody titer was elevated. He was diagnosed with DCMP with GD; treatment with methylprednisolone, diuretics, inotropics, and methimazole was initiated. The EF improved after the TFT normalized. At follow-up several months later, although the TFT results again showed evidence of hyperthyroidism, his EF had not deteriorated. His cardiac function continues to remain normal 1.5 months after treatment was started, although he still has elevated T3 and high TSH receptor antibody titer levels due to poor compliance with drug therapy. To summarize, we report a young child with GD-induced DCMP who recovered completely with medical therapy and, even though the hyperthyroidism recurred several months later, there was no relapse of the DCMP.

Keywords: Dilated cardiomyopathy, Child, Graves disease

\section{Introduction}

Graves disease (GD) is an autoimmune thyroid disease that leads to hyperactivity of the sympathetic nervous system, resulting in heat intolerance, tachycardia, hypertension, and a raised metabolic state ${ }^{1)}$. Dilated cardiomyopathy (DCMP) is a rare but life-threatening condition in children caused by various factors, including viral infections, drugs, metabolic diseases, and autoimmune diseases. In one epidemiologic study in children, $27 \%$ of DCMP cases were due to viral myocarditis ${ }^{2)}$. Rheumatic fever, inflammatory bowel disease, and systemic lupus erythematosus have also been reported as causes of myocarditis in children ${ }^{2}$. Although GD has been reported to cause DCMP in adults, the mechanism has not been documented precisely. There have been several reports of adults with DCMP due to GD, as well as of infants with congestive heart failure secondary to transient neonatal thyrotoxicosis ${ }^{3-6)}$. Most of these patients are reported to have recovered completely after a euthyroid state was established, although a few of the adult patients died ${ }^{5)}$. The infants with transient neonatal thyrotoxicosis went into remission after the maternal antibodies disappeared ${ }^{5)}$. There have been only a few reports of childhood GD combined with cardiomyopathy, and most of the patients with severe cardiomyopathy have $\operatorname{died}^{7)}$. Because of concerns about relapse, almost all of the GD patients who recover from DCMP underwent radioactive iodine ablation, with 
resultant permanent hypothyroidism. To date, there has been no report in literature of GD-induced DCMP in a child that was managed successfully with drug therapy alone. We report the case of a young boy who developed DCMP due to GD. He recovered completely with medical treatment, and although the hyperthyroid state recurred several months later, there was no relapse of the DCMP.

\section{Case report}

A 32-month-old boy was brought to the emergency department with complaints of irritability, vomiting, and diarrhea for 3 days. He had been previously healthy, although he had reportedly lost weight (about $2 \mathrm{~kg}$ ) over the last 3 months. At presentation, the child had an anxious look and was sweating profusely. His height was $101 \mathrm{~cm}$ (1.9 height standard deviation score [SDS]) body weight was $11.3 \mathrm{~kg}(-1.97$ weight SDS), and body mass index (BMI) was 11.08 (-4.69 BMI SDS). The heart rate was 170 beats $/ \mathrm{min}$, the body temperature $36.9^{\circ} \mathrm{C}$, and the blood pressure 110/90 $\mathrm{mmHg}$ (systolic, 90th-95th percentile; diastolic, $>95$ th percentile). On physical examination, he had warm, moist skin and a slightly enlarged but non tender thyroid gland without nodules. He did not have exophthalmos. Cardiovascular examination revealed a rapid regular heart rate with a pansystolic murmur and gallop. The liver was palpable about $3 \mathrm{~cm}$ below the right subcostal margin and was tender.

The child had been born by normal vaginal delivery, with a birth weight of $3.0 \mathrm{~kg}$. There was no significant prenatal history. His two elder sisters and his parents had no history of cardiac or autoimmune diseases.

An electrocardiogram confirmed sinus tachycardia (167/ min) and revealed low-amplitude QRS complexes. The chest radiograph showed cardiomegaly with interstitial pulmonary edema (Fig. 1A). The echocardiogram revealed a dilated left ventricle, with moderate mitral and tricuspid regurgitation. The estimated left ventricular ejection fraction (EF) was $28 \%$. He was diagnosed as a case of DCMP with congestive cardiac failure and was admitted for further evaluation and treatment. We started treatment with fluid restriction (to 60\% of maintenance), a diuretic (furosemide, $2 \mathrm{mg} / \mathrm{kg} / \mathrm{day}$ ), an angiotensin converting enzyme inhibitor (captopril, $0.5 \mathrm{mg} /$ $\mathrm{kg} / \mathrm{day}$ ), and inotropics (dopamine, $10 \mu \mathrm{g} / \mathrm{kg} / \mathrm{min}$; digoxin, $25 \mu \mathrm{g} / \mathrm{kg}$ ). Initial laboratory findings revealed that the white blood cell count was $19,760 / \mathrm{mm}^{3}$, segmented neutrophils $26.9 \%$, hemoglobin $12 \mathrm{~g} / \mathrm{dL}$, and platelet count $342,000 / \mathrm{mm}^{3}$. The serum aspartate aminotransferase (AST) and alanine aminotransferase (ALT) levels were elevated at 654 and 1,140 $\mathrm{U} / \mathrm{L}$, respectively. The total bilirubin level was $1.6 \mathrm{mg} / \mathrm{dL}$, and the prothrombin time was 24.4 seconds ( $28 \%$ of normal control, 2.22 international normalized ratio). The pro-brain natriuretic peptide (Pro-BNP) level was $25,277 \mathrm{pg} / \mathrm{mL}$ (normal range, $<115$ $\mathrm{pg} / \mathrm{mL}$ ). The thyroid function test (TFT) showed a free T4 level of $3.52 \mathrm{ng} / \mathrm{dL}$ (normal range, $0.7-1.48 \mathrm{ng} / \mathrm{dL}$ ), T3 level of 1.22 $\mathrm{ng} / \mathrm{mL}$, and a thyroid stimulating hormone (TSH) level of 0.0002
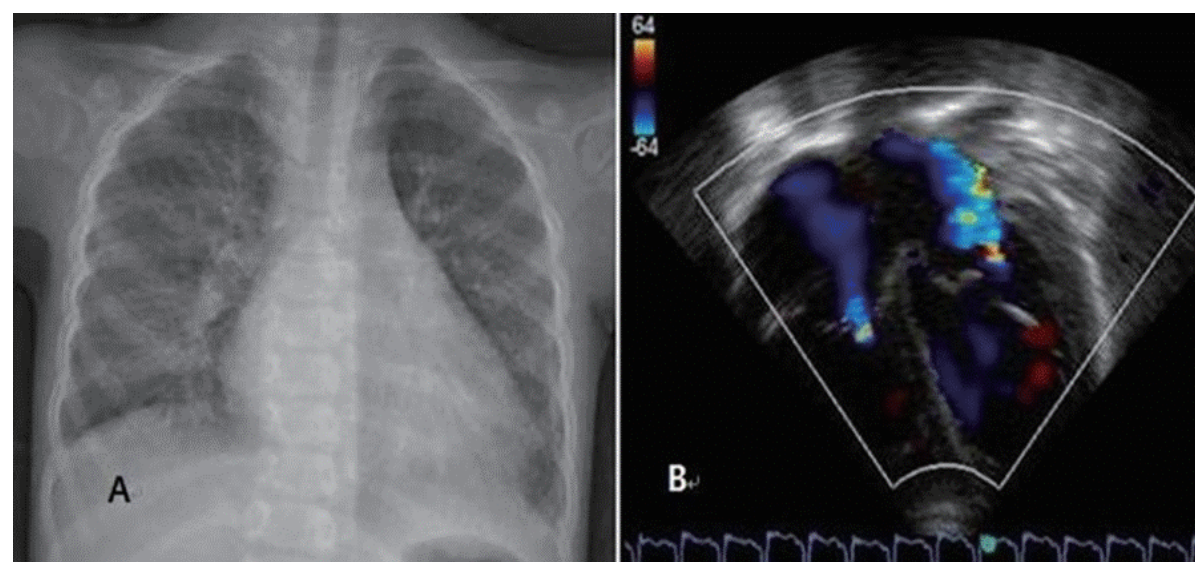

Fig. 1. (A) Chest roentgenogram shows cardiomegaly and pulmonary edema and (B) echocardiography shows severe atrioventricular valves regurgitation and cardiomegaly on apical 4-chamber view.

Table 1. Summary of the laboratory findings of the patient

\begin{tabular}{lcccc}
\hline Laboratory finding & Admission & 1.5 Months later & Recurrence (3 months later) & 8 Months later \\
\hline Free T4 $(\mathrm{ng} / \mathrm{dL})$ & 3.52 & 1.97 & 3.96 & 0.84 \\
T3 $(\mathrm{ng} / \mathrm{mL})$ & 1.22 & 2.88 & 4.63 & 1.57 \\
TSH $(\mu \mathrm{lU} / \mathrm{mL})$ & 0.0002 & 0.0009 & 0.0001 & 0.0011 \\
TSH receptor antibody (IU/L) & 33.29 & $>40.00$ & $>40.00$ & $>40.00$ \\
AST (IU/L) & 654 & 35 & - & 36 \\
ALT (IU/L) & 1,140 & 22 & - & 28 \\
Ejection fraction (\%) & 28 & 54 & 52.6 & $>60$ \\
\hline
\end{tabular}

$\mathrm{TSH}$, thyroid stimulating hormone; AST, aspartate aminotransferase; ALT, alanine aminotransferase. 
$\mu \mathrm{IU} / \mathrm{mL}$ (normal range, $0.35-4.94 \mu \mathrm{IU} / \mathrm{mL}$ ). The TSH receptor antibody was positive at $33.29 \mathrm{IU} / \mathrm{L}$ (normal range, $<1.75 \mathrm{IU} /$ $\mathrm{L}$ ), and the thyroid peroxidase antibody titer level was $45.50 \mathrm{IU} /$ $\mathrm{mL}$ (normal range, $0-30 \mathrm{IU} / \mathrm{mL}$ ). Based on these findings, we arrived at a diagnosis of hyperthyroidism due to GD and started the child on methimazole $(0.5 \mathrm{mg} / \mathrm{kg})$. We also considered that the DCMP was caused by the GD, and put the patient on highdose intravenous methylprednisolone $(30 \mathrm{mg} / \mathrm{kg} /$ day $)$ for 3 consecutive days. We tried administering Lugol solution, but had to discontinue it because of the frequent vomiting. Propranolol was delayed until circulatory stabilization was achieved, because it can cause severe hypotension in cases of low-output cardiac failure

On the second day, thyroid ultrasonography was performed and showed a large area of heterogeneous echogenicity with a 0.2 -cm-size cyst in the lower portion of the right lobe of the thyroid gland. Viral study for Epstein-Barr virus, cytomegalovirus, enterovirus, and hepatitis virus A and B were all negative, but was positive for respiratory adenovirus. The serum immunoglobulin levels were in the normal range, although the $\mathrm{C} 4$ and CH50 levels were decreased at $9.4 \mathrm{mg} / \mathrm{dL}$ and $15.9 \mathrm{U} /$ $\mathrm{mL}$, respectively. Antinuclear antibody, double-stranded DNA antibody, and antismooth muscle antibody were negative.

On the fifth day, the boy was doing well: the vomiting and diarrhea had subsided, and his vital signs had stabilized; the liver was still palpable $1 \mathrm{~cm}$ below the right subcostal margin but was no longer tender. The AST and ALT levels had decreased to 50 and $139 \mathrm{U} / \mathrm{L}$, respectively, and the pro-BNP level was $686.3 \mathrm{pg} / \mathrm{mL}$. Follow-up echocardiography on the eighth day of hospitalization showed an EF of 54\%. The repeat TFT showed a free T4 level of $1.74 \mathrm{ng} / \mathrm{dL}$ and a TSH level of $0.0006 \mu \mathrm{IU} /$ $\mathrm{mL}$. The dose of methylprednisolone was tapered over 7 days. A follow-up chest radiograph on the eighth day of hospitalization revealed decrease in the heart size and reduction in the bilateral pulmonary edema (Fig. 1B). Furosemide, dopamine, and digoxin were discontinued, and propranolol $(0.5 \mathrm{mg} / \mathrm{kg} /$ day $)$ was started on day 8 . On day 12 , the boy was discharged on propranolol, methimazole $(0.4 \mathrm{mg} / \mathrm{kg} /$ day $)$, and captopril, with instructions to taper off the dosages of propranolol and captopril gradually.

At 3 months, the boy had recurrence of hyperthyroidism as the mother was no longer administering the methimazole regularly for 1 month. The free T4 was elevated to $3.96 \mathrm{ng} / \mathrm{dL}$ and the T3 to $4.63 \mathrm{ng} / \mathrm{mL}$; the TSH was depressed to 0.0001 $\mu \mathrm{IU} / \mathrm{mL}$. TSH receptor antibody titer was elevated to more than $40 \mathrm{IU} / \mathrm{L}$. Despite this, however, the patient did not have any hear failure symptom, and echocardiography showed an EF of 52.6\%, with only mild mitral regurgitation. We increased the dose of methimazole to $0.5 \mathrm{mg} / \mathrm{kg} /$ day, tapering the dosage gradually to a maintenance dose of $0.2 \mathrm{mg} / \mathrm{kg} /$ day after TFT was normalized. The latest TFT, 3 years after the initial diagnosis, shows free T4, $0.98 \mathrm{ng} / \mathrm{dL} ; \mathrm{T} 3,1.68 \mathrm{ng} / \mathrm{mL}$; and TSH, $0.0012 \mu \mathrm{IU} / \mathrm{mL}$. The TSH receptor antibody titer remains high at $>40 \mathrm{IU} / \mathrm{L}$. The patient continues to do well on $0.2 \mathrm{mg} / \mathrm{kg} /$ day of methimazole, and his latest echocardiography shows normal cardiac function, with no evidence of regurgiation (Table 1).

\section{Discussion}

We present the case of a child with DCMP due to GD who recovered completely with medical treatment and whose cardiac complications did not aggravate in spite of recurrence of hyperthyroidism.

Severe cardiac complications are rare in GD. The incidence of severe cardiomyopathy in adults with GD is only $5.8 \%$ according to one report ${ }^{8}$. Boccalandro et al..$^{5}$ reported that cardiomyopathy in hyperthyroidism may be more common in the middle-aged patient and may occur in the absence of underlying heart disease. Most patients recover completely with medical treatment after a euthyroid state is achieved. Medical treatment generally includes diuretics, inotropic agents, propranolol, and antithyroid drugs, with recovery times varying from several weeks to several months ${ }^{5)}$. However, some patients with cardiomyopathy due to hyperthyroidism have died in spite of medical treatment ${ }^{9,10)}$. Childhood GD is not as common as the adult form and, moreover, the incidence of severe cardiac complications is also lower, being seen in only $1 \%$ of these patient ${ }^{7}$. Cavallo et al. ${ }^{7}$ reported that 2 of 21 children with hyperthyroidism had congestive heart failure. One of the 2 patients, who was diagnosed with hyperthyroidism at 12 years of age, underwent subtotal thyroidectomy but deteriorated because of cardiac complications and died of possible cerebral embolism. The second patient was 17 years old and had normal cardiac examination results at the initial evaluation. However, 5 years later, his hyperthyroidism recurred and was accompanied by congestive heart failure. He underwent radioactive iodine treatment but died, nevertheless, of heart failure.

Unlike the other complications of GD, cardiomyopathy is life-threatening and therefore most of the patients who recover from cardiomyopathy are advised to undergo radioactive iodine ablation or thyroidectomy ${ }^{3-6)}$. However, our patient did not undergo thyroidectomy or radioactive iodine ablation. We did consider ablation after he recovered from the DCMP but decided to persist with antithyroid drug therapy considering his young age. Although his hyperthyroidism recurred due to irregular medication, the heart failure did not relapse.

The mechanism of cardiomyopathy in GD has not been clearly documented. Some studies have demonstrated that prolonged hyperthyroidism, with the attendant chronic tachycardia and arrhythmias, may be the cause of the cardiomyopathy in $\mathrm{GD}^{4)}$. On the other hand, Mavrogeni et al. ${ }^{11)}$ have documented lymphocyte infiltration in endomyocardial biopsy and suggested that an autoimmune mechanism may be involved. Koshiyama et al. ${ }^{12}$ identified TSH receptor mRNA in the heart of a patient with cardiomyopathy and GD. These findings suggest that autoimmunity might contribute to the cardiomyopathy seen in GD. Although we did not do an endomyocardial biopsy in our patient, on echocardiography the EF did not decrease despite elevation of the TSH receptor antibody titer. Additionally, this child was young, and he had probably had hyperthyroidism for only about $2-3$ months before he was diagnosed. Acute viral infection also causes acute myocarditis, and respiratory 
adenovirus was positive in the present patient. He also had vomiting and diarrhea for 2 days, however, he did not have fever and other respiratory symptoms and they were disappeared on the second day of admission. Acute respiratory adenovirus infections typically include sore throat, rhinorrhea, and fever, whereas sometimes there might be asymptomatic infection. We regarded GD was more possible cause of DCMP than respiratory adenovirus in the present case from the clinical findings, however we could not ignore the possibility of the viral cause.

Corticosteroids can be used as adjuvant therapy in a thyroid storm or in hyperthyroidism-induced cardiomyopathy for decreasing thyroid hormone release and reducing the inflammatory response $\mathrm{e}^{13)}$. Although our patient did not have a thyroid storm, we used high-dose corticosteroid to treat his DCMP at the initial diagnosis itself, and his cardiac status and TFT values improved rapidly. It is recommended for $300 \mathrm{mg}$ of hydrocortisone in thyroid storm ${ }^{13}$, whereas highdose corticosteroids might be considered in acute fulminant myocarditis ${ }^{14)}$. In the present case, pediatric cardiologist saw the patient first, thus high-dose methylprednisolone was preferentially conducted to the patient unaware of the Graves' disease. The patient was recovered rapidly with intensive treatment. The TFT usually normalizes within 1.5-3 months of initiating antithyroid drug treatment. In this case, however, the TFT improved within 7 days of start of treatment. We suggest that this rapid normalization of the TFT was due to the early treatment with high-dose corticosteroid.

In summary, in this paper we report the case of a young boy with DCMP due to GD who was successfully managed with drug therapy alone. We propose that early treatment with corticosteroid can be useful in the management of the patient with GD-induced DCMP, and that with such management the DCMP may not relapse after recovery even if the hyperthyroidism does recur. Therefore, in case of young children, medical treatment with close follow-up could be preferentially considered than surgical resection or ablation.

\section{Conflict of interest}

No potential conflict of interest relevant to this article was reported.

\section{References}

1. Weetman AP. Graves' disease. N Engl J Med 2000;343:1236-
48.

2. Durani Y, Giordano K, Goudie BW. Myocarditis and pericarditis in children. Pediatr Clin North Am 2010;57: 1281-303.

3. Shapiro S, Steier M, Dimich I. Congestive heart failure in neonatal thyrotoxicosis. a curable casue of heart failure in the newborn. Clin Pediatr (Phila) 1975;14:1155-6.

4. Al-Ghamdi AS, Aljohani N. Graves' thyrotoxicosis-induced reversible cardiomyopathy: a case report. Clin Med Insights Case Rep 2013;6:47-50.

5. Boccalandro C, Boccalandro F, Orlander P, Wei CF. Severe reversible dilated cardiomyopathy and hyperthyroidism: case report and review of the literature. Endocr Pract 2003;9:140-6.

6. Khandwala HM. A case of congestive heart failure due to reversible dilated cardiomyopathy caused by hyperthyroidism. South Med J 2004;97:1001-3.

7. Cavallo A, Joseph CJ, Casta A. Cardiac complications in juvenile hyperthyroidism. Am J Dis Child 1984;138:479-82.

8. Siu CW, Yeung CY, Lau CP, Kung AW, Tse HF. Incidence, clinical characteristics and outcome of congestive heart failure as the initial presentation in patients with primary hyperthyroidism. Heart 2007;93:483-7.

9. Magner JA, Clark W, Allenby P. Congestive heart failure and sudden death in a young woman with thyrotoxicosis. West J Med 1988;149:86-91.

10. Shirani J, Barron MM, Pierre-Louis ML, Roberts WC. Congestive heart failure, dilated cardiac ventricles, and sudden death in hyperthyroidism. Am J Cardiol 1993;72:365-8.

11. Mavrogeni S, Markussis V, Bratis K, Mastorakos G, Sidiropoulou EJ, Papadopoulou E, et al. Hyperthyroidism induced autoimmune myocarditis: evaluation by cardiovascular magnetic resonance and endomyocardial biopsy. Int J Cardiol 2012;158:166-8.

12. Koshiyama H, Sellitti DF, Akamizu T, Doi SQ, Takeuchi Y, Inoue D, et al. Cardiomyopathy associated with Graves' disease. Clin Endocrinol (Oxf) 1996;45:111-6.

13. Bahn RS, Burch HB, Cooper DS, Garber JR, Greenlee MC, Klein I, et al. Hyperthyroidism and other causes of thyrotoxicosis: management guidelines of the American Thyroid Association and American Association of Clinical Endocrinologists. Endocr Pract 2011;17:456-520.

14. JCS Joint Working Group. Guidelines for diagnosis and treatment of myocarditis (JCS 2009): digest version. Circ J 2011;75:734-43. 